\title{
LA CIUDADANÍA DESDE EL PENSAMIENTO SOCIAL RELIGIOSO COMPARADO ISLAMOCRISTIANO
}

Fecha de recepción: 18 de mayo de 2019

Fecha de aceptación y versión final: 18 de junio de 2019

RESUMEN: El concepto de ciudadanía, en cuanto pertenencia a una comunidad política, es un concepto de carácter secular fruto de la modernidad occidental y clave para una sana separación entre la religión y la política. Sin embargo, las tradiciones religiosas pueden ayudar a comprender con más profundidad este concepto. Desde una perspectiva de teología comparada la tradición política secular y las tradiciones cristiana e islámica de pensamiento político tienen mucho que aprender unas de otras. Cristianismo e islam son iluminadas desde la idea secular de ciudadanía para profundizar en la justa diferenciación religión-política. Por su parte, ambas tradiciones religiosas, cada una a su manera, enseñan a la tradición secular a ver a la persona como una unidad que incluya su dimensión religiosa y a ver la ciudadanía como abierta a la realidad de la familia humana.

PALABRAS CLAVE: ciudadanía; Estado; nación; dignidad humana; umma; Magisterio social; laicidad; teología comparada.

\footnotetext{
Facultad de Teología de Granada: gvillagran@jesuitas.es; ORCID: https://orcid. org/0000-0002-7942-7175 


\section{Citizenship Seen from Islamic-Christian Compared Religious Social Thought}

ABSTRACT: Citizenship, meaning belonging to a political community, is a concept of secular origin, fruit of the Western modernity and a key for a healthy distinction between religion and politics. Nevertheless, religious traditions can help to get a deeper understanding of this concept. From a comparative theology perspective, the tradition of secular political thought and Christian and Muslim traditions of political thought have a lot to learn from each other. On the one hand, Christianity and Islam can be enlightened from the secular idea of citizenship as a way to deepen in a just differentiation between religion and politics. On the other hand, both religious traditions, each one in its own way, help the secular tradition to look at the human being as whole, including its religious dimension, as well as to understand the concept of citizenship as open to the reality of the entire human family.

KEY WORDS: citizenship; State; nation; human dignity; umma; social teaching; laicity; compared theology.

La categoría de ciudadanía se puede considerar como un horizonte último de cualquier proceso de integración de migrantes en una sociedad. La socióloga Saskia Sassen, en un espléndido estudio, describe la comprensión de la integración de los migrantes que ha habido en Europa que ha pasado de la mera consideración de trabajadores temporales hasta la plena participación de los migrantes como actores políticos y como políticos mismos ${ }^{1}$. Comenta también Sassen cómo actualmente se están barajando nuevas comprensiones de ciudadanía que sean capaces de recoger la realidad de las migraciones globales.

A la vez que la ciudadanía es el objetivo último y el marco teórico en que pensar la integración, se da el hecho de que la población musulmana de los países europeos tiene dificultades para asumir plenamente ese marco conceptual. Así, José M. ${ }^{a}$ Contreras describe cómo la segunda generación de migrantes de origen musulmán en los países europeos, a pesar de ser ciudadanos de pleno derecho, tienen dificultades para encontrar su lugar en la sociedad y pueden terminar

${ }^{1}$ Cf. Saskia Sassen, Inmigrantes y ciudadanos. De las migraciones masivas a la Europa fortaleza (Madrid: Siglo XXI, 2013), 193-95. 
desarrollando identidades esquizofrénicas con rasgos seculares occidentales fuera de casa y tradicionales musulmanes en la familia ${ }^{2}$.

Una de las causas ${ }^{3}$ de esta dificultad de los jóvenes musulmanes para articular sus identidades religiosa y política pasa por lo extraño de la categoría de ciudadanía para la tradición islámica. De alguna manera, para muchos musulmanes la ciudadanía activa y dinámica a que se invita en las sociedades occidentales es algo ajeno al ideal de vida social recibido de sus padres. Hay, por lo tanto, una tarea importante en ayudar a avanzar en un diálogo entre la visión de la política en las democracias pluralistas y la tradición religiosa islámica.

Sin embargo, este diálogo no hay que verlo como un diálogo unidireccional donde el pensamiento político occidental impusiera a la tradición islámica, y otras tradiciones religiosas, sus dogmas. En el paradigma intercultural e interreligioso que debe ser el nuestro hay que pensar esa influencia como una influencia recíproca entre tradiciones religiosas y tradiciones seculares.

Como contribución a la reflexión sobre esta aproximación a la ciudadanía, quiero en este artículo presentar tres aproximaciones a dicho concepto: la aproximación del pensamiento político secular, la aproximación desde la tradición católica y, finalmente, la aproximación desde la tradición islámica. El desplegar en paralelo estas tres visiones nos permitirá captar el núcleo del concepto que nos ocupa y sus límites, y ver cómo ha sido interpretado en las principales tradiciones religiosas presentes en España. Esta interpretación a veces puede ser limitada, pero otras pueden incluso superar la idea secular primera. En un último momento, intentaré presentar algunas

2 «Por su parte, la llamada "segunda generación” está integrada por personas que, en muchos casos, adoptan la religión de sus padres y defienden su derecho a tener las mismas posibilidades de practicar su religión que cualquier joven cristiano, por ejemplo. No obstante, éstos se encuentran con dificultades para integrar la religión, de modo que de lunes a viernes funcionan con los marcos cívicos y educativos españoles, y los fines de semana lo hacen con los del país de origen de sus padres, lo que genera un conflicto de difícil solución», José M. ${ }^{a}$ Contreras Mazarío, ¿Hacia un islam español? Un estudio de derecho y política (Valencia: Tirant lo Blanch, 2017), 43.

3 No podemos ignorar otras causas más bien externas de esta dificultad de la comunidad musulmana como son la falta de reconocimiento o el tratamiento permanente como personas a «integrar» aun cuando tratamos con la segunda generación, ya plenamente integrada en el país, cf. Contreras Mazarío, 128. 
reflexiones comparativas a la luz de esta presentación. Como quedará claro, de fondo hay una opción por un acercamiento a esta pluralidad de comprensiones desde un marco de teología comparativa ${ }^{4}$, en concreto de pensamiento social religioso comparado ${ }^{5}$.

\section{EL CONCEPTO DE CIUDADANÍA}

En la filosofía de la edad moderna, el término ciudadano se define en contraste con el concepto de ser humano - al que corresponden los derechos humanos- y en relación con el concepto de soberanía. Al salir del estado de naturaleza por medio del contrato social, se instaura una soberanía en la nueva sociedad que lleva a considerar a las personas que la forman como ciudadanos, miembros del nuevo cuerpo político. Al pasar de seres humanos a ciudadanos, la filosofía de la edad moderna consideraba que se daba una necesaria priorización de los intereses comunes de la sociedad sobre los particulares. Así, la consideración de ciudadano por un lado supone una mayor responsabilización de lo común y, por otro, una mayor protección por parte de la sociedad de sus derechos ${ }^{6}$.

En línea con este contexto, el moralista Julio Martínez define la ciudadanía como, en sus palabras, «un modo de inserción de las personas en la sociedad política; una relación política entre un individuo y una comunidad, en virtud de la cual el individuo es miembro de pleno derecho de esa comunidad y le debe lealtad $»^{7}$. De una manera más sintética Ignacio Sepúlveda habla de ciudadanía como «un reconocimiento oficial de la integración del sujeto en la comunidad política a la cual pertenece» ${ }^{8}$. El mismo

${ }^{4}$ Francis X. Clooney, Comparative Theology: Deep Learning Across Religious Borders (Malden, MA: Wiley-Blackwell, 2010).

5 Gonzalo Villagrán, Conversaciones transformadoras: Una metodología para el diálogo islamo-cristiano en el campo del pensamiento social religioso, Discursos Inaugurales (Granada: Facultad de Teología de Granada, 2017).

6 Cf. Lucien Jaume, "Citoyenneté", en Dictionaire de philosophie politique (París: PUF, 2003), 96.

7 Julio L. Martínez, Ciudadanía, migraciones y religión: Un diálogo ético desde la fe cristiana (Madrid: San Pablo-Universidad Pontificia de Comillas, 2007), 79.

8 Ignacio Sepúlveda, "La construcción ética de la ciudadanía cosmopolita. La práctica democrática hoy en día: Posibilidades y límites”, en Humanismo y ética básica, ed. Ignacio Sepúlveda (Bilbao: Desclée de Brouwer-UNIJES, 2017), 152. 
Sepúlveda identifica diferentes dimensiones implicadas por este concepto de ciudadanía: la ciudad política o plena participación en los derechos políticos de un país, la ciudadanía social o posibilidad de beneficiarse de la protección de un Estado de bienestar concreto, la ciudadanía económica o posibilidad de influir en la toma de decisiones económicas que afecten a uno, y la ciudadanía civil o plena participación en la sociedad civil de un país $^{9}$. Para el tratamiento que hacemos en este trabajo del concepto de ciudadanía nos interesa sobre todo la plena ciudadanía política.

El hecho de que la ciudadanía es el modo de inserción en la comunidad política - que ya vemos que suele conllevar también la ciudadanía social, económica y civil—, y de que esta inserción no esté abierta a todos, supone para Martínez que la ciudadanía implica últimamente posición y privilegio ${ }^{10}$. Esta cualidad de la ciudadanía se pone en tensión y lleva a situaciones contradictorias, cuando aparecen en escena los movimientos migratorios globales actuales.

Derek Heater añade que el concepto de ciudadanía supone también identidad, en cuanto que hace a la persona sentirse parte de un grupo humano, una identidad política capaz de integrar otras identidades previas de la persona (religiosa, étnica...). Además, ciudadanía para Heater implica también una cierta virtud pues la plena maduración moral del individuo requiere desarrollar una responsabilidad social y una conciencia del bien común que la ciudadanía implica ${ }^{11}$.

La ciudadanía como categoría personal es para Martínez un concepto mediador entre el Estado y la nación ${ }^{12}$. Ricard Zapata-Barrero desarrolla esta idea y habla de una relación triádica de los conceptos po-

9 Cf. Sepúlveda, 158-69.

10 «La ciudadanía es, por tanto, posición y privilegio... Son ciudadanos hoy quienes tienen derechos a determinadas cosas por el hecho de pertenecer a una comunidad exclusiva, esto es, no abierta a todos. Cuando se definen las condiciones de acceso a la ciudadanía, necesariamente, se están haciendo explícitas las condiciones de exclusión de otros», Martínez, Ciudadanía, migraciones y religión, 85.

${ }_{11}$ Cf. Derek Heater, Citizenship: The Civic Ideal in History, Politics and Education, $3^{\text {rd }}$ ed. (Manchester: Manchester University Press, 2004), 187-89.

12 «El Estado como formación política que sobre un territorio de límites definidos ejerce las funciones legales, administrativas y penales al más alto nivel y como entidad política que define quién es ciudadano y limita territorialmente su actividad. Y la nación como entidad simbólica que vincula culturalmente el territorio estatal con la ciudadanía, creando la lealtad y cohesión necesarias para que el vínculo entre el Estado y la ciudadanía sea permanente y estable a través del tiempo. La ciudadanía 
líticos de Estado, nación y ciudadanía que encarna el paradigma político ilustrado dentro del cual nos pensamos en cuanto democracia. Para Zapata-Barrero este triángulo determina los sistemas de valores políticos de nuestras democracias modernas occidentales, así como el espacio de certidumbre político fuera del cual solo hay desorientación ${ }^{13}$.

En este triángulo, en palabras de Zapata-Barrero, el Estado sería «la entidad política que define quién es ciudadano y qué limita territorialmente su actividad», la nación, «la entidad simbólica que vincula culturalmente el territorio estatal con la ciudadanía, creando la lealtad y cohesión necesarias para que el vínculo entre el Estado y la ciudadanía sea permanente y estable a través del tiempo». La ciudadanía «juega en este marco un papel mediador» por ser «el principal vehículo que tiene el Estado y la Nación para vincularse y legitimarse» ${ }^{14}$. La ciudadanía podríamos definirla como, en sus palabras, «una identidad necesaria para que una autoridad pueda relacionarse con una pluralidad de personas, pero independientemente del tipo de organización política» ${ }^{15}$. La ciudadanía no solo supone el estar vinculado jurídica y políticamente al Estado, lo que ocurre también en el residente; la ciudadanía implica también unos derechos políticos que solo los ciudadanos pueden tener ${ }^{16}$. Para nuestro autor, los tres conceptos no pueden concebirse por separado pues cada concepto se define y limita por medio de los otros dos y que cada concepto sirve de mediador para los otros $\operatorname{dos}^{17}$.

Así, para Zapata-Barrero, esta relación tan estrecha entre Estado, nación y ciudadanía tiene una doble lectura. Una lectura institucional en cuanto que este triángulo sirve de referencia y límite para el ejercicio del poder político al determinar el marco de la legalidad, el ejercicio del poder y los límites del demos. Otra lectura sería una lectura normativa al ser este triángulo conceptual la referencia de los valores éticos, de nuestros paradigmas políticos y de la aplicación real de la democracia ${ }^{18}$.

desempeña un papel mediador, siendo el principal medio que tienen Estado y nación para vincularse y legitimarse», Martínez, Ciudadanía, migraciones y religión, 93.

13 Cf. Ricard Zapata-Barrero, "La ciudadanía en contextos de multiculturalidad: Procesos de cambios de paradigmas", Anales de la Cátedra Francisco Suárez 37 (2003): 175-79.

14 Zapata-Barrero, 175.

15 Zapata-Barrero, 179.

16 Cf. Zapata-Barrero, 180.

17 Cf. Zapata-Barrero, 176.

18 Cf. Zapata-Barrero, 176-77. 
El jurista catalán llama la atención de cómo el fenómeno actual del multiculturalismo - en cuanto a la mayor pluralidad cultural y religiosa de las sociedades- socaba los cimientos de este triángulo conceptual al mostrar lo irreal de pensar que el demos de una sociedad sea igual al total de la población o que sea culturalmente homogéneo. Estos presupuestos, la igualdad de ciudadanía, demos y nacionalidad, están a la base de la visión ilustrada del Estado-nación-ciudadanía pues permiten definir unos límites claros a la población y a la autoridad política ${ }^{19}$. Esta supuesta igualdad es lo que permite pensar la ciudadanía como una categoría básicamente excluyente, lo que es muy problemático en las sociedades plurales actuales. De esta manera, con frecuencia en las sociedades actuales se da un doble estatus entre la población de un Estado: una parte de la población es residente en el país, y solo algunos gozan de la ciudadanía que les permite tener derechos políticos.

La evidente ruptura actual de la igualdad entre ciudadanía, demos y nacionalidad ha llevado a algunos autores en filosofía política a buscar nuevas comprensiones de la ciudadanía capaces de integrar la diferencia entre los miembros de las sociedades multiculturales, se trata de la corriente llamada comunitarista. El principal y más sugerente autor en este campo es Charles Taylor. Taylor sugiere, para las sociedades plurales actuales, la necesidad de conjugar el reconocimiento de la mutua diferencia con el compartir ciertos valores y acuerdos fundamentales, estos valores y acuerdos compartidos se generan sobre todo a través de la vida política participativa ${ }^{20}$. Por lo tanto, para Taylor, la ciudadanía en sociedades plurales requiere reconocer la diferencia, pero abrirse a compartir una base común de comprensión de la vida política. Esta concepción se hace muy interesante e iluminadora cuando pensamos en sociedades muy plurales religiosamente. Igualmente, esta visión incita a las comunidades religiosas a hacer un esfuerzo por apropiarse unos valores centrales comunes a toda la población de una sociedad, de alguna

19 Cf. Zapata-Barrero, 177.

20 «Unirse en el mutuo reconocimiento de la diferencia — es decir, del valor igual de identidades diferentes- requiere que compartamos algo más que la creencia en este principio; hemos de compartir también ciertas normas de valor en las que las identidades en cuestión se demuestran iguales... cómo desarrollar y preservar los rasgos de valores comunes a nosotros se convierte en algo importante, y una de las formas cruciales de llevar a cabo esto consiste en compartir una vida política participativa», Charles Taylor, La ética de la autenticidad (Barcelona: Paidós, 2002), 86. 
manera ese es el proceso que se da con el concepto de ciudadanía en el cristianismo y el islam.

Por otra parte, hemos también de mirar cómo se declina el concepto de ciudadanía cuando miramos más allá de las sociedades concretas hacia el conjunto de la humanidad. Derek Heater, desde una visión bastante positiva de la ciudadanía, considera que podemos pensar también en desarrollar una ciudadanía cosmopolita que nos haga sentir parte del género humano ${ }^{21}$. Esta identidad tendría la capacidad de subsumir toda otra identidad evitando muchas tensiones. Para Heater, esta identidad podría sostenerse en una conciencia de la historia de la humanidad como una historia común, y un fin común de hacer frente a los desafíos de la humanidad. Esta identidad estaría apoyada en la tradición de los derechos humanos. Sin embargo, Heater estaría hablando aquí más de un sentimiento de identidad que de una ciudadanía efectiva y reconoce la dificultad de un sentimiento de identidad mundial y su carácter más bien difuso.

La filósofa política Seyla Benhabib hace una propuesta para dar forma a esta demanda de ciudadanía más allá de los límites de la población en un Estado. Benhabib afirma que las democracias liberales se ven cogidas en una tensión entre la validez universal de los derechos humanos que trasciende los límites de las comunidades y las realidades históricas y culturales de los ordenamientos jurídicos civiles de las comunidades. Benhabib invita a establecer un diálogo entre estos dos extremos ${ }^{22}$. Benhabib afirma así que existe un derecho humano a la pertenencia, que sería el opuesto al derecho a no ser desnaturalizado, pero que existe también un derecho de las comunidades a establecer unas condiciones, en términos de competencias adquiridas (cualificación, habilidades, adquisición de la lengua...), para la admisión a la ciudadanía. Ambas condiciones respetan la fundamentación de los derechos según la ética comunicativa porque se podría justificar que se aplicaran a todos, incluidos los actuales ciudadanos ${ }^{23}$. En este sentido, el derecho a la ciudadanía de los seres humanos implicaría que deben existir caminos concretos practicables para alcanzar la ciudadanía, y que existe el derecho a conocer cuáles son los requisitos concretos que se piden y su justificación ${ }^{24}$.

${ }^{21}$ Cf. Heater, Citizenship, 191-94.

22 Cf. Seyla Benhabib, The Rights of Others: Aliens, Residents and Citizens, $9^{\text {th }}$ ed. (Cambridge, U.K.: Cambridge University Press, 2011), 134.

${ }^{23}$ Cf. Benhabib, 138-39.

${ }^{24}$ Cf. Benhabib, 140. 


\section{LA CIUDADANÍA EN EL PENSAMIENTO SOCIAL CATÓLICO}

El Magisterio social católico no se puede asociar a ninguna corriente concreta de filosofía política, pero hay que reconocer que ha aprendido bastante del liberalismo en temas como los derechos humanos, la libertad religiosa, la democracia y los límites del poder del Estado ${ }^{25}$. En ese sentido, el magisterio ha asumido, sin tratarla explícitamente, la categoría de ciudadanía, tan propia del liberalismo. Así, los primeros documentos sobre política y sobre el sistema liberal publicados por un papa, las encíclicas Immortale Dei ${ }^{26}$ y Libertas Praestantissimum ${ }^{27}$ de León XIII ${ }^{28}$, utilizan con naturalidad y asiduidad el término ciudadano para referirse a las personas ${ }^{29}$. Este término se utiliza con conciencia de su diferencia e interrelación con la identidad integral de la persona ${ }^{30}$.

Sin embargo, igualmente de manera explícita, el magisterio ha superado esta categoría muy pronto al afirmar con determinación una visión universalista e internacionalista que ve a toda la humanidad como una sola familia. Así, Juan XXIII en Pacem in Terris ${ }^{31}$, primera encíclica

25 «Catholic social teaching, then, is not to be identified with any one form of political philosophy, though it has clearly learned from liberalism with regards to its teaching on human rights, religious freedom, democracy, and the limited power of the state», John Langan, "Political Philosophy", en The New Dictionary of Catholic Social Thought (Collegeville, MN: Liturgical Press, 1994), 748.

26 Carta Encíclica Immortale Dei (1 noviembre 1885), ASS 18 (1885): 161-180.

27 Carta Encíclica Libertas Praestantissimum (20 junio 1888), ASS 20 (18871888): 593-613.

28 Estos documentos no se suelen incluir en el corpus de documentos que considera el Magisterio social de la Iglesia. Sin embargo, sí se reconoce su carácter pionero en el campo del pensamiento político de la Iglesia, cf. Ildefonso Camacho, Doctrina social de la Iglesia. Una aproximación histórica (Madrid: San Pablo, 1991), 89-102.

29 i.e. «Los derechos de los ciudadanos son respetados como derechos inviolables y quedan defendidos bajo el patrocinio de las leyes divinas, naturales y humanas. Los deberes de cada ciudadano son definidos con sabia exactitud y su cumplimiento queda sancionado con oportuna eficacia. Cada ciudadano sabe que, durante el curso incierto y trabajoso de esta mortal peregrinación hacia la patria eterna, tiene a la mano guías seguros para emprender este camino y auxiliadores eficaces para llegar a su fin». Immortale Dei, 8, ASS 18 (1885): 167-169.

30 «Se imponen también como obligatorias la mutua caridad, la benignidad, la liberalidad. No queda dividido el hombre, que es ciudadano y cristiano al mismo tiempo, con preceptos contradictorios entre sí», Immortale Dei, 8, ASS 18 (1885): 167-169.

31 Carta Encíclica Pacem in Terris (11 abril 1963), AAS 54 (1963): 257-304. 
que trata abiertamente de política y de las relaciones internacionales, afirma en el párrafo 25 que: «El hecho de pertenecer como ciudadano a una determinada comunidad política no impide en modo alguno ser miembro de la familia humana y ciudadano de la sociedad y convivencia universal, común a todos los hombres». Esta visión de la ciudadanía como abierta implica consecuencias en el sentido del reconocimiento de la dignidad humana más allá de tener la ciudadanía en un Estado u otro, así se afirma en el párrafo 25 lo siguiente: «los exiliados políticos poseen la dignidad propia de la persona y se les deben reconocer los derechos consiguientes, los cuales no han podido perder por haber sido privados de la ciudadanía en su nación respectiva» ${ }^{32}$. El magisterio social, por tanto, afirma con fuerza aquí la base en la dignidad humana de derechos que solemos asociar a la pertenencia a una comunidad política.

Esto lleva más allá la visión liberal del papel central del Estado nación, y conduce a afirmar la existencia de un bien común de la familia humana ${ }^{33}$ y la necesidad de una autoridad mundial ${ }^{34}$. Estas afirmaciones de la encíclica Pacem in Terris (PT) serán confirmadas en la síntesis del Magisterio Social Católico que supone la Constitución Gaudium et Spes (GS) ${ }^{35}$ del Vaticano $\mathrm{II}^{36}$.

Es necesario reconocer que el Magisterio Social de la Iglesia no ha tratado explícitamente el concepto de ciudadanía a pesar de ser un

32 AAS 54 (1963): 263.

33 «Ninguna época podrá borrar la unidad social de los hombres, puesto que consta de individuos que poseen con igual derecho una misma dignidad natural. Por esta causa, será siempre necesario, por imperativos de la misma naturaleza, atender debidamente al bien universal, es decir, al que afecta a toda la familia humana», "Pacem in Terris", 132, AAS 54 (1963): 292.

34 "Y como hoy el bien común de todos los pueblos plantea problemas que afectan a todas las naciones, y como semejantes problemas solamente puede afrontarlos una autoridad pública cuyo poder, estructura y medios sean suficientemente amplios y cuyo radio de acción tenga un alcance mundial, resulta, en consecuencia, que, por imposición del mismo orden moral, es preciso constituir una autoridad pública general», "Pacem in Terris", 137, AAS 54 (1963): 293.

35 "Constitución Pastoral Gaudium et Spes (7 diciembre 1965)", AAS 58 (1966): 1025-1120.

36 "Gaudium et Spes", 77-84, AAS 58 (1966): 1100-1108. «Catholic social teaching has been consistently universalist and internationalist (PT 130-145) This takes it beyond the preoccupation of most political philosophy with the construction and legitimacy of the nation-state», Langan, "Political Philosophy", 746. 
concepto clave del modelo político liberal ${ }^{37}$. Es posible, sin embargo, trazar algunas líneas claves de la comprensión de la sociedad según el Magisterio social que nos permitan imaginar cómo puede entender este la ciudadanía.

El profesor Julio Martínez se esfuerza en hacer esto en su libro Ciudadanía, migraciones y religión al identificar los puntos clave del Magisterio social. Así, para él la clave de dicho magisterio es la dignidad humana como característica esencial de todo ser humano, de toda persona, sujeto y fin de toda la actividad social ${ }^{38}$. En este sentido basta recordar cómo el Compendio de la Doctrina Social de la Iglesia (CDSI) ${ }^{39}$ considera el principio de la dignidad humana como origen y fundamentación de todos los demás principios de la Doctrina Social ${ }^{40}$. La dignidad humana está basada en una común naturaleza humana de todos los hombres y mujeres creados a imagen y semejanza de Dios (Gn 1,26). Puesto que el Magisterio social entiende al hombre como esencialmente social, que es el centro de la sociedad, y que la dignidad de la persona es la base de toda la moral, nos permite pensar la visión del Magisterio social como un personalismo solidario ${ }^{41}$ en el cual, a partir de la dignidad humana, se afirman una serie de principios sociales (solidaridad, subsidiariedad, bien común) y valores que marcan la vida social (igualdad, libertad y participación $)^{42}$.

37 «Hay que advertir, de entrada, que la DSI [Doctrina Social de la iglesia] no ha tematizado explícitamente su modelo de ciudadanía, lo cual no es óbice para que, a partir de las categorías y temas normalmente asociados a ese concepto, se puedan encontrar con fruto elementos que nos permitan avanzar en su bosquejo», Martínez, Ciudadanía, migraciones y religión, 287.

38 «El punto de partida y centro de la DSI es siempre la persona, como sujeto y fin de toda la actividad social... Considerar a la persona humana como fundamento y fin de la comunidad política significa trabajar, ante todo, por el reconocimiento y el respeto de su dignidad mediante la tutela y la promoción de los derechos fundamentales e inalienables del hombre», Martínez, 287-88.

39 Pontificio Consejo Justicia y Paz, Compendio de la Doctrina Social de la Iglesia.

40 «[El] principio de la dignidad de la persona humana... en el que cualquier otro principio y contenido de la doctrina social encuentra fundamento», CDSI, 160.

41 «[L]a dignidad de la persona... es el fundamento no sólo de la ética social, sino de toda la moral, porque la persona es el gran valor que ha de ser respetado, siempre y cuando no perdamos de vista que la persona es no sólo individuo singular, insustituible e irrepetible, sino ser relacional, comunitario, creado por la comunión de Dios, comunidad de personas, y para la comunión con la creación», Martínez, Ciudadanía, migraciones y religión, 291.

42 Cf. Martínez, 291. 
El Magisterio social afirma por tanto el bien común de la sociedad como la dimensión social del bien moral ${ }^{43}$. El bien común afectaría al individuo y a todos los niveles de la vida en sociedad (familia, asociación, ciudades...). Sería el criterio para juzgar y limitar la iniciativa y la búsqueda de bienestar individual.

El bien común es para el Compendio un principio social al que debe referirse toda la vida social y que queda definido, siguiendo a GS, como «el conjunto de condiciones de la vida social que hacen posible a las asociaciones y a cada uno de sus miembros el logro más pleno y más fácil de la propia perfección» (CDSI, 164). Julio Martínez destaca, en su síntesis, que este bien común correspondería a la sociedad civil, y que la comunidad política, a la que nos incorporamos por la ciudadanía, se constituiría para servir a dicha sociedad civil ayudando a conseguir el bien común ${ }^{44}$. Por ello mismo, la comunidad política debe dar prioridad de iniciativa a la sociedad civil como afirma el principio de subsidiariedad.

El fin de la comunidad política debe ser, en palabras de Martínez, actuar «a favor de la creación de un ambiente humano en el que se ofrezca a los ciudadanos la posibilidad del ejercicio real de los derechos humanos y del cumplimiento pleno de los respectivos deberes ${ }^{45}$. Por lo tanto, al considerar el Magisterio social que el centro de la acción de la comunidad política es la dignidad humana, dignidad que trasciende dicha comunidad, para el Magisterio social la pertenencia a la comunidad por medio de la ciudadanía no puede ser un absoluto.

En coherencia con esta visión de la sociedad nacional que se apoya en fundamentos éticos de carácter universal, el Magisterio social de la Iglesia ha desarrollado una visión ética universalista que supera el marco nacional y asciende en el campo de las relaciones internacionales. Así, como ya hemos visto, desde PT, primera encíclica propiamente política y que reflexionaba también sobre el orden mundial, el Magisterio social ha afirmado abiertamente la existencia de un nivel del bien común que podríamos llamar global, el bien común de la familia humana. En aquella encíclica Juan XXIII afirmaba también que este nivel del bien común es también un bien moral que exige la cooperación internacional, que incluya una autoridad mundial (PT 137), y el esfuerzo de todas las naciones para favorecerlo. Esta dimensión

\footnotetext{
43 Cf. Martínez, 292.

44 Cf. Martínez, 292.

45 Martínez, 293.
} 
mundial de la vida en sociedad y la comunidad que le corresponde, la familia humana, desborda el concepto de ciudadanía política que estamos considerando.

Pero más allá de esta dimensión mundial, aún en el nivel de las sociedades nacionales, el concepto de ciudadanía, siendo valioso, se ve desbordado por las consideraciones éticas. Así, Martínez afirma también cómo la convivencia civil y política en la sociedad, el ejercicio de la ciudadanía, no es solo el fruto de los derechos y deberes de las personas, sino que ha de ser fruto de una auténtica amistad civil que haga real el principio de fraternidad en la sociedad ${ }^{46}$. Luego una visión integral de la idea de ciudadanía tiene unas raíces humanas más profundas y universales de lo que esperaríamos.

Por otra parte, en el Magisterio social el papel del Estado - la entidad que gestiona la ciudadanía y sus derechos- es garantizar la cohesión, unidad y organización de la sociedad civil para que pueda buscar el bien común ${ }^{47}$. Hay que tener en cuenta aquí que el Estado es simplemente una parte de la sociedad civil con una tarea concreta. Esa parte del bien común que corresponde al Estado, que toca más bien la coordinación y organización, se suele denominar el orden público ${ }^{48}$. El Estado está así comprometido con unos mínimos a partir de los cuales pueda surgir el bien común. La relación entre la sociedad y el Estado se daría a través de la democracia por la cual todos participan en la gestión de la cosa pública en libertad ${ }^{49}$. Como es natural la plena participación en el sistema democrático requiere en principio de la ciudadanía.

46 «[E]l n. 390 del CDSI alude al concepto de la amistad civil para señalar que el significado profundo de la convivencia civil y política no surge inmediatamente del elenco de los derechos y deberes de la persona, toda vez que el campo del derecho es el de la tutela del interés y el respeto exterior, el de la protección de los bienes materiales y su distribución según reglas establecidas, y el campo de la amistad es el del desinterés, el desapego de los bienes materiales, la donación y la disponibilidad. Es decir, la amistad civil es el campo del principio de fraternidad, que se une y redimensiona a los principios de libertad e igualdad», Martínez, 295.

47 Cf. Martínez, 295. Así se afirma en CDSI 168.

48 «El Concilio explicitó que si el bien común corresponde al conjunto de la sociedad civil, a la parte del bien común que cae dentro de la competencia del Estado le llama orden público: el nivel mínimo de cohesión social necesario para que la sociedad en toda su diversidad pueda tender hacia la construcción del bien común», Martínez, 296.

49 Cf. Martínez, 297. 
Esta visión sintética de la comprensión de la vida social del Magisterio de la Iglesia implica una visión de la ciudadanía como abierta y orientada hacia el horizonte de una ciudadanía mundial. Esta ciudadanía abierta ha de incluir necesariamente un trato de respeto al emigrante y una cultura de acogida y diálogo ${ }^{50}$. Por lo tanto, la posición del pensamiento social católico presenta claramente el horizonte ético de una ciudadanía humana, más allá de la ciudadanía política de una sociedad concreta, que tenga como base el reconocimiento de los derechos humanos ${ }^{51}$.

\section{LA CIUDADANÍA EN EL PENSAMIENTO SOCIAL ISLÁMICO}

Hay que decir que el islam, hablando con rigor, no conoce la categoría de ciudadanía ${ }^{52}$. Esta es una categoría más bien ajena al pensamiento clásico político islámico que no se puede asimilar a otras concepciones propias de la tradición islámica ${ }^{53}$. La concepción islámica de la sociedad más bien divide a esta en función de la religión: musulmanes y no musulmanes. Los no musulmanes son tratados con la categoría de dim-

50 «[C] ${ }^{2}$ ando los emigrantes son tratados con el debido respeto de la dignidad de toda persona; cuando se favorece con todos los medios la cultura de la acogida y la cultura de la paz, que armoniza las diferencias y busca el diálogo, sin caer en forma de indiferencia cuando los valores están en cuestión, estamos en la vía de una ciudadanía abierta y capaz de generar un marco político-jurídico de acogida. Esta apertura solidaria se convierte en ofrecimiento y en condición de paz», Martínez, 304.

51 «Reivindicar una "ciudadanía humana", más allá de su reconocimiento jurídico-político, es el presupuesto implícito de la afirmación incondicional de los derechos humanos como base y referencia fundamental del diálogo en la diversidad moral, cultural y religiosa... Es una exigencia ética nacida de la proclama universalista de los derechos humanos que la política debe asumir como proyecto viable en la construcción de un nuevo orden mundial», Martínez, 582.

52 "[C]lassical Islam, strictly speaking, did not know citizenship», Nawaf Salam, "The Emergence of Citizenship in Islamdom", Arab Law Quarterly 125 (1997): 134.

53 "Citizenship is a modern Western notion that does not fully fit into political interpretations of Islam. The modern perception of citizenship as a relation between the state and the individual ignores the importance of group identity in both classical and modern notions of citizenship in Islam». Jennifer Mitchell, "Citizenship", en The Princeton Encyclopedia of Islamic Political Thought, ed. Gerhard Bowering (Princeton: Princeton University Press, 2013), 94-95. 
mís ${ }^{54}$, lo que supone entenderlos como protegidos por el islam, pero con un estatus de ciudadanos de segunda ${ }^{55}$.

Esta concepción de la ciudadanía como vinculada más bien a la religión, favorece una comprensión trasnacional de la ciudadanía que lleva a los musulmanes a considerarse antes miembros de la umma, el conjunto de los creyentes en el islam, que de un país concreto ${ }^{56}$. Esto afecta también a los musulmanes viviendo como minorías en países de tradición no musulmana, que se debaten entre la integración en dichas sociedades o en privilegiar más bien su pertenencia a la $u m m a^{57}$.

Nawaf A. Salam considera que la noción moderna de ciudadanía está directamente vinculada a la concepción y reconocimiento del individuo $^{58}$. Esta valoración del individuo incluye el valor absoluto del individuo, la valoración positiva de la vida privada, así como una invitación a tomarse a uno mismo como objeto de mejora, trabajo y salvación.

Salam reconoce, en cuanto a la primera dimensión del valor del individuo, que existe una tensión en el islam entre el individuo y la comunidad. Esta tensión sería una concreción de una tensión mayor

54 «Traditionally, the relationship of dhimmîs to the government is contractual: they are given rights and freedoms as citizens of the state based on their political submission to the Islamic state... it is clear that their position as citizens is different from, and inferior to, that of Muslims», Mitchell, 95.

55 «Individuals relate to the state based on whether they are Muslim or non-Muslim. This emphasis on a corporate identity derives from the classical emphasis on the umma, or the Muslim community, and the notion of the ahl al-kitâb (People of the Book), or religious minorities recognized by Islam and often referred as dhimmîs. The rights and duties of each of these groups were different, and usually only Muslims were allowed full participation in the state», Mitchell, 95.

56 "The focus on the umma allows for a transnational emphasis on Muslim citizenship. Mawdudi tried to emphasize this approach by claiming that in areas that are considered dâr al-Islâm (abode of Islam), a Muslim is a citizen by virtue of the fact that he or she is part of the Muslim umma and not by birth in that country», Mitchell, 95.

57 «This view of citizenship as based on membership in the Muslim community also affects Muslims living in non-Muslim lands. In debates over how Muslims should relate to their country of residence and its government, some groups advocate complete separation from their non-Muslim host society... Others... have argued for full civic and political participation by Muslims citizens of Western countries», Mitchell, 95.

58 Cf. Salam, "The Emergence of Citizenship in Islamdom”, 128. 
propia del islam entre su mensaje universal y la organización tribal de la sociedad propia de sus sociedades ${ }^{59}$.

Así, en el islam se da, por una parte, un gran interés en la personalidad y el carácter del individuo, heredado de los tiempos preislámicos (jahiliyya). Esto se refrenda cuando el Corán, a pesar de otras consideraciones más negativas sobre el ser humano, lo considera últimamente como virrey y representante de Dios (khalifah) sobre la creación $(C 2,30)^{60}$.

Esta estima tan alta del individuo coincide, por otra parte, con una valoración igualmente elevada de la comunidad de los creyentes (umma) y de su unidad, lo que implica solidaridad entre los creyentes y conformidad con las normas de la comunidad ${ }^{61}$.

Aunque con frecuencia, los autores orientalistas consideraban que últimamente era la dimensión comunitaria la que se imponía en la vivencia del islam sobre el individuo, Nawaf Salam considera que, a través del estudio del tratamiento del individuo en la tradición legal islámica, vemos que más bien la tensión individuo-comunidad se mantiene sin resolverse.

Así, Salam subraya como el derecho islámico protege la propiedad privada, aún frente al mismo Estado, así como protege también las herencias $^{62}$. Además, las mismas fuentes religiosas hablan de rechazar la obediencia en caso de que implique pecado. En la tradición de pensamiento islámico también encontramos un papel muy importante del individuo en el sufismo y la falasifat, o tradición de pensamiento filosófico islámico de inspiración griega clásica ${ }^{63}$.

Sin embargo, Salam reconoce que en la evolución histórica del pensamiento político islámico se ha dado una tendencia a conceder mayor preponderancia a la unidad y cohesión de la umma que al individuo, buscando proteger a la comunidad islámica y evitar cualquier división en ella (fitna). Esto llevó, por ejemplo, a algunos teólogos a afirmar abiertamente que era necesario obedecer al gobernante, aunque este fuera un tirano y actuara mal moralmente ${ }^{64}$. Sin embargo, siempre quedó un reducto en este pensamiento para la protección del individuo.

\footnotetext{
${ }^{59}$ Cf. Salam, 129-30.

${ }^{60}$ Cf. Salam, 130.

61 Cf. Salam, 129.

62 Cf. Salam, 132.

63 Cf. Salam, 133.

${ }^{64}$ Cf. Salam, 132.
} 
Otra dimensión necesaria para la ciudadanía es la igualdad ante la ley de todos los ciudadanos. Esta igualdad no está plenamente presente en la tradición islámica. Así, la tradición islámica identifica dos tipos de igualdad diferentes entre los seres humanos. Por una parte, la igualdad de los seres humanos en cuanto tales, en cuanto criaturas creadas de arcilla por Dios. Esta igualdad no da ningún derecho a las personas y es vista más bien negativamente. Por otra parte, está la igualdad de los creyentes en cuanto miembros de la umma, esta igualdad supera cualquier diferencia humana de raza, estatus o medios económicos e iguala a los seres humanos según su religiosidad (C 49,13).

Por ello existe una desigualdad fundamental entre los creyentes musulmanes y los no musulmanes de una misma población regida según la tradición islámica. Los miembros de la umma tienen derechos políticos, los no musulmanes, son considerados dimmís (protegidos) que implica un estatus de segunda clase con menos derechos y obligaciones ${ }^{65}$. Junto con esto hay que tener en cuenta que tanto las mujeres como los esclavos no tienen el mismo grado de igualdad que los demás miembros de la $u m m a^{66}$.

Por otra parte, la comprensión del poder político en el islam como legitimado directamente de Dios, el único auténtico soberano y el legislador del islam, hace que la idea de participación en el gobierno esté muy limitada en el islam.

La fundamentación de la autoridad viene así de la implementación de la ley divina. Las posibilidades de participación de la población en el gobierno se dan en campos muy limitados: juramento de lealtad al líder (bay'a), consultas (shura) y búsquedas de consenso (ijma'). Estos espacios de participación estaban abiertos tan solo a una cierta élite y, con el tiempo, se fueron haciendo menos y menos importantes ${ }^{67}$.

A pesar de la distancia cultural y teórica real entre el concepto de la tradición política de ciudadanía y la visión política islámica, Salam considera que se dan los elementos en la tradición islámica para el desarrollo de una concepción como la de ciudadanía. Este autor destaca así elementos de la tradición islámica como el reconocimiento del carácter único del ser humano, la responsabilidad personal, una cierta concepción del respeto a los derechos individuales civiles, una herencia de la

\footnotetext{
${ }^{65}$ Cf. Salam, 134.

${ }^{66}$ Cf. Salam, 135.

67 Cf. Salam, 135-36.
} 
cultura árabe preislámica que ensalza la personalidad individual, la influencia de corrientes más individuales como el sufismo y la Mu'tazilah o la influencia de la filosofía griega. Todas estas características del islam pueden ser la base para el desarrollo de un concepto moderno de ciudadanía a pesar de la distancia cultural ${ }^{68}$.

Como prueba de esta potencialidad positiva de la tradición islámica, Salam presenta el ejemplo del desarrollo político prooccidental del Imperio Otomano en la época del edicto de Tanzimat (en turco reforma, reorganización) del Sultán Abdulmecit I en $1839^{69}$. Hasta ese momento, como en tantos países de tradición islámica, se entendía la población del imperio como dividida entre los súbditos musulmanes y, en un segundo lugar, las diferentes minorías religiosas protegidas distribuidos en comunidades religiosas diferentes (millet) y tratados como ciudadanos de segunda. Las reformas del Tanzimat buscaban proteger la seguridad, la vida, el honor y la fortuna de los súbditos del imperio, así como homogeneizar y universalizar el cobro de impuestos y el reclutamiento del ejército. Estas medidas se aplicaban por igual a todos los súbditos del imperio independientemente de su religión, lo que implicaba superar el modelo de millet y reconocer últimamente el concepto de ciudadanía.

Estos avances en el plano de la igual consideración de todos los súbditos del Imperio Otomano no solo supusieron introducir una idea muy cercana a la ciudadanía, sino que, con el tiempo, llevaron también a la introducción de la idea de representatividad y a un cierto parlamentarismo que culminó con la Constitución de 1876. Esta Constitución instauró una cámara de diputados elegidos por la población ${ }^{70}$. Aunque en 1878 el sultán suspendió la Constitución, en 1908 volvió a instaurarse una cámara parecida.

Para Salam todo esto es un ejemplo de los profundos cambios producidos en el islam por el contacto con Occidente desde finales del siglo

68 "It remains true, however, that the recognition by Islam of the moral uniqueness of man, of his individual responsibility and of the sanctity of his "civil" rights, together with the inherited interest from Arab antiquity in personality and character and the influence of ideas such as those of the Sufi(s), the Mu'tazilah, and the Falasifat, all formed conditions leading to the emergence of the autonomous and independent individual that citizenship presupposes», Salam, 133.

${ }^{69}$ Cf. Antony Black, The History of Islamic Political Thought: From the Prophet to the Present (New York, NY: Routledge, 2001), 280-84.

${ }^{70}$ Cf. Salam, “The Emergence of Citizenship in Islamdom”, 142-44. 
$\mathrm{XVIII}^{71}$. La conciencia de la distancia cultural, económica y militar con Occidente fue lo que llevó al Imperio Otomano a atreverse a realizar este tipo de reformas institucionales. Sin embargo, no podemos ignorar otra importante influencia ideológica que explica el Tanzimat: la influencia del movimiento nacionalista del siglo XIX en el Imperio Otomano que llevó a buscar entender la fundamentación del imperio no en el islam, sino en la nacionalidad otomana o otomaneidad ${ }^{72}$. Este mismo fomento del sentimiento nacional terminó minando las reformas del Imperio Otomano al fomentar también nacionalismos periféricos en otras zonas del imperio (Siria, Egipto, Líbano, Túnez...) que terminaron separándose ${ }^{73}$.

Más allá de este ejemplo histórico del final del Imperio Otomano, la potencialidad de la tradición islámica para acoger el concepto de ciudadanía, a pesar de no estar presente en las fuentes del islam, ha quedado demostrada en los últimos treinta años por varios pasos importantes dados desde instancias significativas de la comunidad islámica. Estos pasos han supuesto afirmar de manera cada vez más explícita el concepto de ciudadanía como componente del ideal social islámico contemporáneo.

Así, en primer lugar, en 1990 la Conferencia Islámica ${ }^{74}$ aprobó la Declaración del Cairo sobre derechos humanos en el islam ${ }^{75}$ como reinterpretación de la Declaración Universal de Derechos Humanos de las Naciones Unidas para el contexto islámico ${ }^{76}$. Dicho documento es un paso de apropiación de los conceptos políticos seculares y el paradigma de los derechos humanos por parte del islam. Sin embargo, hay que reconocer que es claramente insuficiente, pues subordina todas sus afirmaciones a la Shari'a islámica (art. 24), la que considera única fuente de clarificación de los derechos humanos (art. 25). Sin embargo, podemos

${ }^{71}$ Cf. Salam, 136.

72 "Osmanlilik was intended to salvage the unity of al empire then threatened by upheavals from within its borders as much as from European interventions. It attempted to convey an idea of patriotism based on brotherhood and equality», Salam, 141.

${ }^{73}$ Cf. Salam, 142.

74 Actualmente denominada Organización para la Cooperación Islámica (OIC)

75 "Cairo Declaration on Human Rights in Islam", University of Minnesota Human Rights Library, consultada el 23 de diciembre de 2015, http://www1.umn.edu/ humanrts/instree/cairodeclaration.html

76 Existe un documento anterior titulado Declaración Islámica Universal de los Derechos Humanos elaborado en 1981 bajo los auspicios del Consejo Islámico, sin embargo, los expertos consideran que refleja menos un consenso entre las distintas posiciones islámicas que la Declaración del Cairo, cf. Ann Elisabeth Mayer, Islam and Human Rights: Tradition and Politics, 4. ${ }^{\mathrm{e}}$ ed. (Boulder, CO: Westview, 2007), 28-33. 
encontrar afirmaciones importantes que suponen una afirmación implícita del concepto de ciudadanía. Así se da a entender la existencia de una cierta pertenencia política de los individuos a la sociedad, independientemente de su religión, que genera obligaciones del Estado frente a ellos. Así, se afirma que todos los individuos son iguales ante la ley (art. 19), o que todo el mundo tiene derecho a vivir con seguridad en cuanto a su persona o su religión (art. 18), derecho del que debe ser garante el Estado. Igualmente se afirma el derecho de todos a participar en la administración de los asuntos públicos de su país (art. 23), aunque se afirma que esto debe hacerse según las indicaciones de la Shari'a $a^{77}$.

En segundo lugar, debemos fijarnos en la llamada Declaración de Marrakech sobre los derechos de las minorías religiosas en comunidades donde predominen mayorías musulmanas publicada en $2016^{78}$. Esta declaración, más explícita y clara que el documento anterior, es el fruto del encuentro de un grupo de intelectuales musulmanes de diferentes países, auspiciado por el rey Mohamed VI de Marruecos, para celebrar el 1400 aniversario de la Constitución de Medina $^{79}$. Históricamente se ha considerado como la inspiración última del pensamiento político musulmán tradicional. La Declaración de Marrakech considera que la Constitución de Medina implicaba últimamente una afirmación de importantes principios vinculados con el concepto de ciudadanía: libertad de movimiento, propiedad privada, solidaridad y defensa mutua, así como justicia e igualdad ante la ley. Esto supone ya aceptar el concepto de ciudadanía como clave hermenéutica para interpretar la tradición islámica misma. El documento pide también, tanto a los intelectuales islámicos como a los políticos, el desarrollo de un concepto de ciudadanía que sea inclusivo de los diferentes grupos religiosos existentes en la sociedad y fortalezca los lazos sociales. De fondo se está invitando a superar la concepción del pensamiento político musulmán clásico de dimma o protección de las minorías religiosas (dimmíes), que de hecho se aso-

${ }^{77}$ Luz Gómez afirma claramente que la Declaración del Cairo, al supeditar todas sus afirmaciones a la Sharía, no garantiza ni la libertad religiosa ni la igualdad ante la ley de los no musulmanes, cf. Luz Gómez, "Dimmí”, en Diccionario de islam e islamismo, ed. Luz Gómez (Madrid: Trotta, 2019).

78 "Marrakesh Declaration", 2016, http://marrakeshdeclaration.org/

${ }^{79}$ La Constitución de Medina es el pacto de conciliación que firmó Mahoma con la población de la ciudad de Medina al instalarse allá tras abandonar la Meca que recoge los deberes y derechos de los miembros de la comunidad, cf. Luz Gómez, "Constitución de Medina”, en Diccionario de islam e islamismo, ed. Luz Gómez (Madrid: Trotta, 2019). 
cia con la Constitución de Medina, sustituyéndola por la plena igualdad de todas las personas al considerarlos ciudadanos de la misma sociedad.

Finalmente, tendríamos que hacer mención también al Documento sobre la fraternidad humana por la paz mundial y la convivencia común ${ }^{80}$ firmado en 2019 en Abu Dabi conjuntamente por el papa Francisco y el gran imam de la mezquita de Al-Azhar, Ahmad Al-Tayyeb. Aunque se trata de un documento interreligioso, el hecho de que haya sido firmado por el gran imán de Al-Azhar, aceptando por tanto su contenido, le da un valor como interpretación de la tradición islámica. En dicho documento se afirma los siguiente:

«El concepto de ciudadanía se basa en la igualdad de derechos y deberes bajo cuya protección todos disfrutan de la justicia. Por esta razón, es necesario comprometernos para establecer en nuestra sociedad el concepto de plena ciudadanía y renunciar al uso discriminatorio de la palabra minorías, que trae consigo las semillas de sentirse aislado e inferior; prepara el terreno para la hostilidad y la discordia y quita los logros y los derechos religiosos y civiles de algunos ciudadanos al discriminarlos».

Como vemos, el documento recoge la llamada de la Declaración de Marrakech a superar la visión de la sociedad como compuesta de mayorías y minorías religiosas, y a hacerlo a través del concepto de ciudadanía en cuanto pertenencia política común de todos los miembros de la sociedad a esta. Este documento interreligioso denuncia y rechaza también la discriminación que supone el tratamiento de los miembros de las minorías religiosas en cuanto tales al dañar sus derechos religiosos y civiles. En esta afirmación encontramos una defensa implícita de los derechos humanos comunes de todos los individuos independientemente de su religión, lo que parece superar los límites de estos que parecería poner la Declaración del Cairo que veíamos anteriormente.

Por lo tanto, podemos afirmar que en ámbitos muy significativos e influyentes de la comunidad musulmana (rey de Marruecos, Universidad de Al-Azhar...) se han dado pasos muy explícitos que implican aceptar el concepto de ciudadanía como modelo según el cual pensar la sociedad

80 "Documento sobre la fraternidad humana por la paz mundial y la convivencia común”, Santa Sede, 4 de febrero de 2019, http://w2.vatican.va/content/francesco/ es/travels/2019/outside/documents/papa-francesco_20190204_documento-fratellanza-umana.html 
desde el islam. Estos ámbitos políticos e intelectuales a los que hacemos referencia no se pueden considerar como ejemplos aislados de individuos de pensamiento particularmente liberal ${ }^{81}$, por el contrario, se trata de instancias e instituciones de gran peso en el islam estándar vivido por muchos millones de musulmanes. Estamos, por lo tanto, siendo testigos de un auténtico proceso de relectura de las fuentes del islam en cuanto a su concepción política.

\section{ALGUNAS REFLEXIONES COMPARATIVAS}

En 2013, los profesores Al-Akiti y Hordern, a partir de un coloquio que había tenido lugar previamente, presentaban un campo de estudio nuevo que invitaban a explorar: el estudio comparativo de las tradiciones de pensamiento político islámicas y cristianas y su relación con el pensamiento secular ${ }^{82}$. El objetivo de este nuevo campo sería profundizar en la comprensión de la vida sociopolítica de ambas religiones para luego enriquecer la reflexión política general de las sociedades plurales modernas. Como campo de estudio estaría situado en el cruce entre la ética religiosa comparada y la teoría política comparada ${ }^{83}$. Una de las intuiciones importantes de las que partían ambos autores, es que las tradiciones religiosas, además de recibir del pensamiento político secular, tienen mucho que ofrecerle a este ${ }^{84}$.

En nuestro caso, este mismo es el marco de reflexión de nuestro artículo, donde hemos querido aproximarnos a la categoría de ciudadanía tanto desde el pensamiento político secular como desde los

${ }^{81}$ La profesora Nelly Lahoud identifica tres corrientes de interpretación de la tradición islámica clásica de pensamiento (turath) en función de cómo la actualizan al momento actual: los islamistas, los apologistas y los intelectuales. Los islamistas hacen una aplicación literal a la actualidad, los apologistas hacen una lectura inclusiva de las fuentes islámicas, y los intelectuales se centran sobre todo en el desarrollo filosófico del pensamiento clásico medieval. A partir de dicha clasificación, podríamos decir que los textos que hemos presentado aquí representan una posición más apologista que intelectual en su lectura de las fuentes islámicas, cf. Nelly Lahoud, Political Thought in Islam: A Study in Intellectual Boundaries (New York, NY: Routledge, 2005), 1-12.

82 Cf. Afifi al-Akiti and Joshua Hordern, "New Conversations in Islamic and Christian Political Thought", The Muslim World 106 (2016): 219-25.

83 Cf. al-Akiti and Hordern, 219.

84 Cf. al-Akiti and Hordern, 220. 
pensamientos sociales católico e islámico ${ }^{85}$. Tres tradiciones claves para configurar la comprensión de este concepto en nuestra sociedad española actual. Ciertamente hemos querido partir del marco del concepto secular de ciudadanía que ha iluminado la historia del pensamiento social católico y ayudado a este a desarrollarse, y que hoy desafía al pensamiento social musulmán y le muestra caminos de crecimiento. Sin embargo, en esta reflexión conclusiva queremos mostrar también que ambas tradiciones de pensamiento social religioso, gracias a su inspiración última y la imaginación propia, desafían también al pensamiento político secular que tiene el peligro de encerrarse en sus propios esquemas lógicos desconectándose de los signos de los tiempos.

En el caso del concepto de ciudadanía podemos hacer algunas reflexiones a partir de la presentación que hemos hecho.

En primer lugar, tenemos que destacar el valor de la categoría ciudadanía en cuanto a identidad política del sujeto. Como tal identidad política la idea de ciudadanía permite superar otras identidades más exclusivas que hagan imposible la convivencia en sociedades plurales. Así, la identidad religiosa tiene a veces el peligro de ser este tipo de identidad exclusiva y el concepto de ciudadanía permite unirnos en la misma sociedad desde otra perspectiva más inclusiva.

Queda así clara la bondad de separar la identidad política de la religiosa, separación que permite el concepto de ciudadanía. Esta separación se vive de manera diferente en las tradiciones religiosas que hemos visto. Así, por una parte, la separación de lo religioso y lo político es un camino que ha ido haciendo el pensamiento social católico desde finales del siglo XIX, sobre todo con el Vaticano II, pero es un camino por el que trabajosamente va avanzando la tradición islámica y en el que se le hace difícil avanzar por la propia visión de la sociedad de su tradición de pensamiento político. Sin embargo, hemos podido mostrar, en primer lugar, que existen signos y casos esperanzadores en la historia de la civilización islámica también desde el siglo XIX en cuanto a la posibilidad de desarrollar un concepto propio de ciudadanía. Por otra parte, en segundo lugar, hemos mostrado que actualmente corrientes sociales e intelectuales principales del islam están ya integrando el concepto de ciudadanía como elemento imprescindible del ideal político que se quiere proponer a la comunidad islámica.

${ }^{85}$ Para un acercamiento similar al concepto de bien común cf. Villagrán, Conversaciones transformadoras. 
Sin embargo, el concepto de ciudadanía no solo supone exigencias y deberes para las tradiciones religiosas, también para la tradición de pensamiento político secular. La visión sinóptica de las tres tradiciones que hemos presentado en este ensayo nos muestra cómo el pensamiento político ha de abrirse a las intuiciones provenientes de la visión religiosa ${ }^{86}$ que ve un horizonte más amplio que el de la sociedad política concreta y buscar una ciudadanía humana universal que responda al desafío que suponen las migraciones globales y el pluralismo.

Así, por una parte, me parece que una llamada de atención importante que hace la mirada religiosa es que esa identidad política no puede ser una identidad aislada. No podemos aislar la dimensión política de la persona del resto de sus otras dimensiones: moral, religiosa... Es necesario ver una cierta continuidad entre unas y otras identidades, aunque no dejen de ser diferentes. Así, vemos como pretender imponer una comprensión de qué es la ciudadanía ajena a las propias visiones de las tradiciones religiosas de la gente, termina por producir una ruptura entre estas comunidades religiosas y la visión que la sociedad quiere imponer. Lo contrario, el diálogo entre el pensamiento político secular y las tradiciones religiosas, permite a estas ir haciendo suyo estos conceptos por medio de una reinterpretación adecuada de sus propias fuentes. Esto lo hemos podido comprobar particularmente en la progresión que percibimos en los documentos recientes islámicos sobre derechos humanos y concepción política como la Declaración de Marrakech.

Por otra parte, me parece claro que la perspectiva de las religiones sobre el tema de la ciudadanía introduce una fuerte llamada a dar consistencia a la idea de una ciudadanía global. La mirada desde las tradiciones religiosas muestra que hay vínculos entre las personas más hondos que los políticos y nos abren a lo que tenemos en común con todo ser humano. En un sentido creyente tendríamos que hablar de la pertenencia a la Iglesia católica o a la umma en el caso musulmán. Además, las tradiciones religiosas estudiadas afirman, de manera explícita en el caso del pensamiento social católico y con explicitud creciente en el caso de las posiciones estudiadas de la tradición islámica, la común dignidad de todo ser humano siguiendo la tradición de los derechos humanos.

Esto nos muestra que no podemos sentirnos ajenos a la situación del otro simplemente porque no pertenezca a la misma comunidad política.

${ }^{86}$ Cf. al-Akiti and Hordern, "New Conversations in Islamic and Christian Political Thought", 220. 
Esto lleva a afirmar la existencia de una comunidad humana mayor que la comunidad política que debe también ser fuente de derechos reales. Esta visión de las tradiciones católica y musulmana iría más allá de la propuesta que hemos presentado de Seyla Benhabib. Mientras la filósofa reconocía el derecho a conocer las exigencias que una sociedad pone para adquirir la ciudadanía, puesto que estaría justificado imponer dichas exigencias a cualquiera, la visión de las tradiciones religiosas pone el acento en la común pertenencia de todos los seres humanos (o al menos de una parte de ellos) a una misma familia. Esta común pertenencia supone que no estarían justificadas condiciones de pertenencia a la ciudadanía solo por el beneficio que recibiera la sociedad de la integración de otro ciudadano. Así, estas condiciones de admisión habrían de ser mínimas y no centradas en el provecho de las sociedades.

De este modo, las tradiciones religiosas estarían empujando en la dirección de reconocer la existencia de una ciudadanía mundial que implica derechos. Hemos visto que esta identidad ciudadana global existe como propuesta y deseo, pero también que está falta de concreción y requiere de un empuje como el que pueden prestarle las religiones.

\section{BIBLIOGRAFÍA}

Akiti, Afifi al-, and Joshua Hordern. "New Conversations in Islamic and Christian Political Thought". The Muslim World 106 (2016): 219-25. DOI: https://doi.org/10.1111/muwo.12155

Benhabib, Seyla. The Rights of Others: Aliens, Residents and Citizens. 9. ${ }^{a}$ ed. Cambridge, U.K.: Cambridge University Press, 2011.

Black, Antony. The History of Islamic Political Thought: From the Prophet to the Present. New York, NY: Routledge, 2001.

"Cairo Declaration on Human Rights in Islam". University of Minnesota Human Rights Library. Consultado el 23 de diciembre de 2015. http:// www1.umn.edu/humanrts/instree/cairodeclaration.html

Camacho, Ildefonso. Doctrina social de la Iglesia. Una aproximación histórica. Madrid: San Pablo, 1991.

Clooney, Francis X. Comparative Theology: Deep Learning Across Religious Borders. Malden, MA: Wiley-Blackwell, 2010.

Contreras Mazarío, José M. ${ }^{a}$ ¿ ¿Hacia un islam español? Un estudio de derecho y política. Valencia: Tirant lo Blanch, 2017. 
"Documento sobre la fraternidad humana por la paz mundial y la convivencia común". Santa Sede, 4 de febrero de 2019. http://w2.vatican. $\mathrm{va/content/francesco/es/travels/2019/outside/documents/papa-fran-}$ cesco_20190204_documento-fratellanza-umana.html

Gómez, Luz. "Constitución de Medina". En Diccionario de islam e islamismo, editado por Luz Gómez, 91. Madrid: Trotta, 2019.

—. "Dimmí". En Diccionario de islam e islamismo, editado por Luz Gómez, 108-9. Madrid: Trotta, 2019.

Heater, Derek. Citizenship: The Civic Ideal in History, Politics and Education. 3. ${ }^{a}$ ed. Manchester: Manchester University Press, 2004.

Jaume, Lucien. "Citoyenneté". En Dictionaire de philosophie politique. París: PUF, 2003.

Langan, John. "Political Philosophy". En The New Dictionary of Catholic Social Thought. Collegeville, MN: Liturgical Press, 1994.

Lahoud, Nelly. Political Thought in Islam: A Study in Intellectual Boundaries. New York, NY: Routledge, 2005.

"Marrakesh Declaration", 2016. http://marrakeshdeclaration.org/

Mayer, Ann Elisabeth. Islam and Human Rights: Tradition and Politics. 4. ${ }^{\text {a }}$ ed. Boulder, CO: Westview, 2007.

Martínez, Julio L. Ciudadanía, migraciones y religión: Un diálogo ético desde la fe cristiana. Madrid: San Pablo-Universidad Pontificia de Comillas, 2007.

Mitchell, Jennifer. "Citizenship". En The Princeton Encyclopedia of Islamic Political Thought, editado por Gerhard Bowering. Princeton: Princeton University Press, 2013.

Salam, Nawaf. "The Emergence of Citizenship in Islamdom". Arab Law Quarterly 125 (1997): 125-47. DOI: https://doi.org/10.1163/0268055 97125825735

Sassen, Saskia. Inmigrantes y ciudadanos. De las migraciones masivas a la Europa fortaleza. Madrid: Siglo XXI, 2013.

Sepúlveda, Ignacio. "La construcción ética de la ciudadanía cosmopolita. La práctica democrática hoy en día: Posibilidades y límites". En Humanismo y ética básica, editado por Ignacio Sepúlveda, 151-83. Bilbao: Desclée de Brouwer-UNIJES, 2017.

Taylor, Charles. La ética de la autenticidad. Barcelona: Paidós, 2002.

Villagrán, Gonzalo. Conversaciones transformadoras: Una metodología para el diálogo islamo-cristiano en el campo del pensamiento social religioso. Discursos Inaugurales. Granada: Facultad de Teología de Granada, 2017. Zapata-Barrero, Ricard. "La ciudadanía en contextos de multiculturalidad: Procesos de cambios de paradigmas". Anales de la Cátedra Francisco Suárez 37 (2003): 173-99. 